\title{
FTIR examination of preservative retention in beech wood (Fagus sylvatica $\mathbf{L}$.)
}

\author{
T. Gołofit · T. Zielenkiewicz $\cdot$ J. Gawron
}

Received: 13 February 2012/Published online: 16 June 2012

(C) The Author(s) 2012. This article is published with open access at Springerlink.com

\begin{abstract}
A method of FTIR examination of preservative retention in beech wood structure was developed. Beech wood samples of different preservative content were prepared using low pressure preservation process in laboratory conditions. Then samples were homogenized in a laboratory mill and measurements were performed using FTIR spectrometer with attenuated total reflectance unit. Pure preservative was also measured and from its spectrum $1,555 \mathrm{~cm}^{-1}$ absorption band was chosen as the characteristic for preservative. 1,027 and $1,370 \mathrm{~cm}^{-1}$ were absorption bands characteristic for wood which were chosen as reference peaks. Values of two absorbance ratios, $\mathrm{A}_{1,555} /$ $A_{1,027}$ and $A_{1,555} / A_{1,370}$ were correlated with the preservative content in particular samples. Correlation coefficients were 0.8390 and 0.8313 , respectively.
\end{abstract}

\section{FTIR-Spektroskopie zur Untersuchung der Schutzmittelaufnahme in Buchenholz (Fagus sylvatica L.)}

\section{Introduction}

Preservative treatment is one of the most important processes in wood industry. There are several treatment

\section{T. Gołofit}

High Energetic Materials Division, Faculty of Chemistry, Warsaw University of Technology, Noakowskiego 3, 00-664 Warsaw, Poland

\section{T. Zielenkiewicz $(\bowtie) \cdot J$. Gawron} Departament of Wood Science and Wood Protection, Faculty of Wood Technology, Warsaw University of Life Sciences, Nowoursynowska 159, 02-787 Warsaw, Poland e-mail: tomasz_zielenkiewicz@sggw.pl variants and preservatives used. However, many of them have been recently withdrawn because of the harmful character of their components. Preservatives based on quaternary ammonium compounds and inorganic alkaline copper (ACQ) are still widely applied for wood preservation. Their behavior, migration, durability, retention and distribution in wood after the treatment have often been examined (Humar and Lesar 2009; Mazela et al. 2007; Zawadzki et al. 2010). Preservative retention and its final distribution in treated object are very important parameters from the process quality point of view. Especially retention needs to be well selected (hazard class) depending on future conditions of treated wood environment. The opportunity to check whether assumed retention is reached or not, is very favorable. In addition, the decrease in preservative content caused by long term slow desorption is an important parameter testifying the preservative and preservation quality. On the other hand, the residual content of active substances in former treated wood must be taken into account prior to utilization of worn-out objects.

The main problem arising during preservation quality testing (i.e., mainly preservative content in wood) is the irregular distribution of active substances in the wood structure. It is well presented in a paper by Zawadzki et al. (2010). So, correct preparation of the sample for analysis is very important. The second task is to choose the instrumental technique of the analysis. ICP, XRF and AAS are three techniques which are often mentioned in literature (Humar and Lesar 2009; Kamdem and McIntyre 1999; Dhamodaran and Gnanaharan 2001) as a good tool for preservative identification as well as its retention and distribution analysis. ICP and XRF are no common equipment in laboratories because of their prize. AAS is more available but needs laborious stage of sample dissolution what may additionally cause unexpected loss of sample parts (volatile compounds are formed). That is 
why in this paper attention was paid to FTIR technique which is relatively inexpensive, commonly used in chemical laboratories and does not need sample dissolution. The analytical process is also quite fast, especially with ATR (attenuated total reflectance) unit. There are known applications of FTIR to analyse the structure of wood components. For example, Zhang and Kamdem (2000) applied FTIR to examine interactions between preservative and structural wood components. They stated that wood interacts with copper ethanolamine preservative and forms copper carboxylate and phenolate complexes, what can be observed in FTIR spectra (changes in absorbance for 1,735, 1,595, 1,710, 1,370 and $1,221 \mathrm{~cm}^{-1}$ bands). However FTIR analysis concerning preservative content in wood is not mentioned in literature.

The aim of this paper is to develop a method of quantitative analysis of copper based preservative (ACQ) in beech wood (Fagus sylvatica L.) using FTIR technique. Realization of this task would give a new method of wood preservative treatment quality testing.

\section{Materials and methods}

30 samples of beech wood (Fagus sylvatica L.) with dimensions of about $5 \times 5 \times 5 \mathrm{~mm}^{3}$ were submitted to model low-pressure preservative treatment using copper based (ACQ), water soluble preservative. Samples were divided into 10 groups of 3. Each group was treated with a different solution of the preservative (from 1 to $20 \mathrm{~g}$ of the preservative in $1,000 \mathrm{~g}$ of water). Samples with specified mass were placed in beakers with solutions. Beakers were located in a Shell Lab vacuum dryer and pressure was reduced to $10 \mathrm{kPa}$. After $20 \mathrm{~min}$ pressure was raised to atmospheric pressure level and samples were left in the solution for consecutive $20 \mathrm{~min}$. Samples were weighed directly after taking out from the solution in order to calculate real content of preservative in wood. Then, after drying at ambient temperature, each sample was placed in a laboratory mill and homogenized. Three measurements of each sample were performed using Thermo Fisher Scientific Inc. Nicolet 6700 FTIR spectrometer with ATR unit. Measurements of pure preservative were also made. To specify the preservative content, absorbance of three bands was analyzed: $1,370,1,027$ and 1,555. Two ratios of absorbance were determined for each measurement: $\mathrm{A}_{1,555} / \mathrm{A}_{1,027}$ (absorbance ratio 1) and $A_{1,555} / A_{1,370}$ (absorbance ratio 2). Correlations between these values and preservative content were found.

\section{Results and discussion}

Figure 1 presents FTIR spectrum of pure ACQ preservative and milled beech wood sample. Based on these measurements, the band located at wave number $1,555 \mathrm{~cm}^{-1}$ (grey line in Fig. 1) was chosen as the characteristic one for this type of preservative. The band with the wave number $1,027 \mathrm{~cm}^{-1}$, as the highest in the beech wood spectrum, was chosen as the reference peak. Another band $\left(1,370 \mathrm{~cm}^{-1}\right)$ was taken into account as the alternative reference peak in order to compare results. The influence of the preservative on several peaks in wood FTIR spectrum was described by Zhang and Kamdem

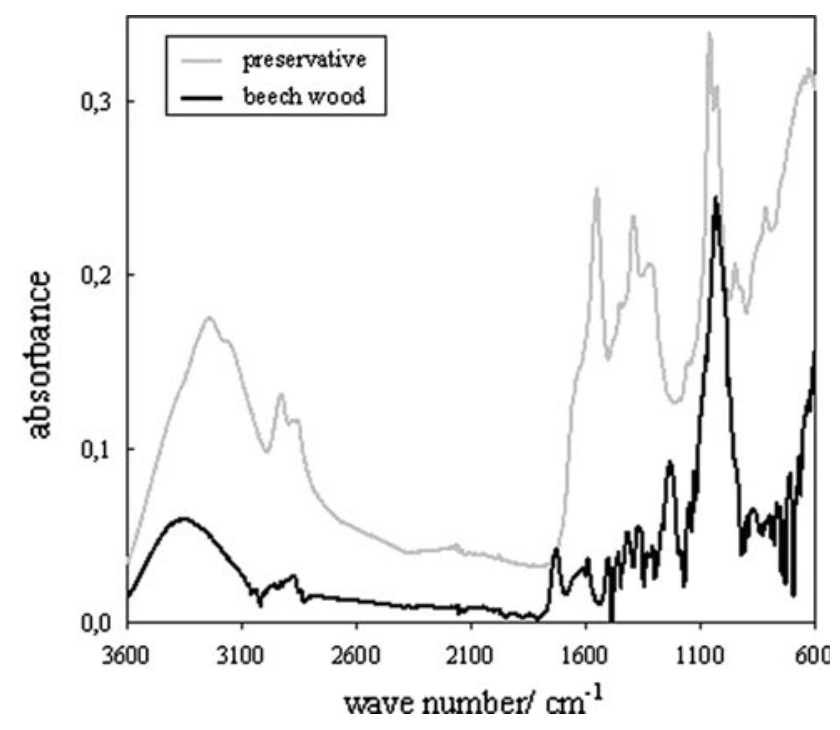

Fig. 1 FTIR spectra of milled beech wood (black line) and ACQtype preservative (grey line)

Abb. 1 FTIR-Spektren von Buchenholz (schwarze Kurve) und von ACQ- Schutzmittel (graue Kurve)

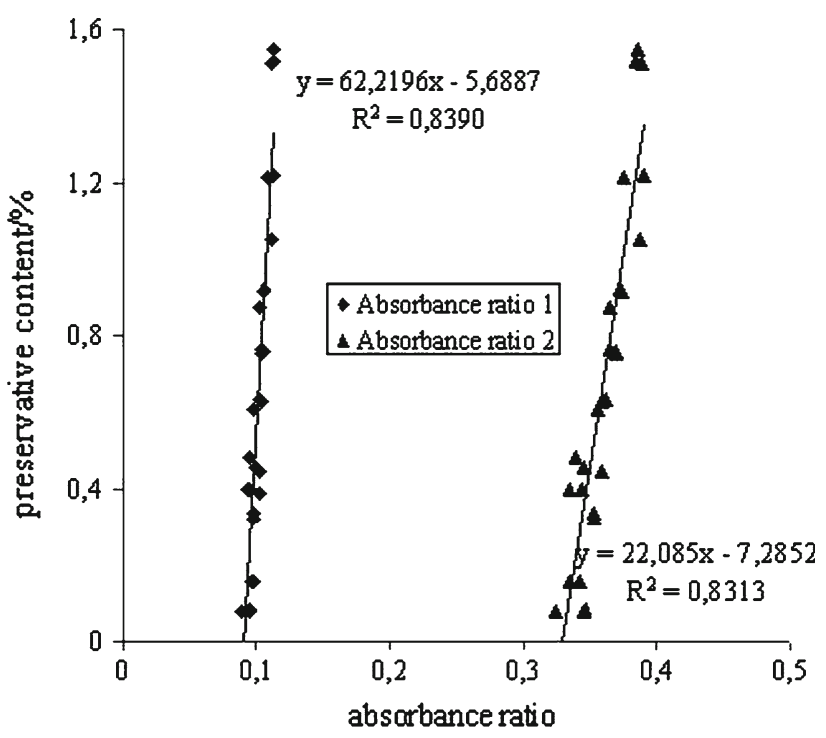

Fig. 2 Correlation between absorbance ratio 1 (left side) and absorbance ratio 2 (right side) and preservative content in beech wood Abb. 2 Korrelation zwischen Absorptionsbandenverhältnis 1 (links) bzw. Absorptionsbandenverhältnis 2 (rechts) und Schutzmittelgehalt im Buchenholz 
(2000). It was assumed that this change is high enough to find a correlation with the preservative content.

Correlation between the absorbance ratio $1\left(\mathrm{~A}_{1,555} /\right.$ $A_{1,027}$ ) and calculated preservative content in wood (based on weighing) is presented in Fig. 2 left side. The correlation coefficient is quite high (0.8390). Figure 2 on the right side shows the same correlation for the absorbance ratio 2 $\left(\mathrm{A}_{1,555} / \mathrm{A}_{1,370}\right)$. Correlation coefficient $(0.8313)$ is on the same level as in the previous case.

\section{Conclusion}

The presented method of preservative content determination is promising for several reasons. First of all, correlation gives quite high correlation coefficients, although "pure", untreated absorbance signal was taken into account. Application of tools available in the equipment software may significantly increase the correlation coefficient value. Secondly, FTIR technique is quite popular and relatively inexpensive so it is widely available as equipment in analytical laboratories. And last, ATR unit used in described experiment makes it quick and handy.

However, it must be emphasized that the range of preservative content in the analysed samples, for the experiment requirements, was much wider than in practice. So the presented method should be developed in the direction of practical application. There is also a need to check whether other types of preservatives can be determined this way.

Open Access This article is distributed under the terms of the Creative Commons Attribution License which permits any use, distribution, and reproduction in any medium, provided the original author(s) and the source are credited.

\section{References}

Dhamodaran TK, Gnanaharan R (2001) Optimizing the schedule for CCA impregnation treatment of rubber wood. Holz Roh Werkst 59:294-298

Humar M, Lesar B (2009) Influence of dipping time on uptake of preservative solution, adsorption, penetration and fixation of copper-ethalonamine based wood preservatives. Eur J Wood Prod 67:265-270

Kamdem DP, McIntyre C (1999) Laboratory evaluation of CDDC as a wood preservative for red oak (Quercus rubra) and red maple (Acer rubrum). Holz Roh Werkst 57:69-72

Mazela B, Domagalski P, Mamonova M, Ratajczak I (2007) Protein impact on the capability of the protein-borate preservative penetration and distribution into pine and aspenwood. Holz Roh Werkst 65:137-144

Zawadzki J, Zielenkiewicz T, Radomski A, Witomski P, Drożdżek M (2010) Testing content of copper in scots pine wood (Pinus sylvestris L.) after preservative treatment. Wood Res 55(4): 91-100

Zhang J, Kamdem DP (2000) FTIR characterization of copper ethanolamine-wood interaction for wood preservation. Holzforschung 54(2):119-122 